\title{
The acceptability of an Internet-based exposure treatment for flying phobia with and without therapist guidance: patients' expectations, satisfaction, treatment preferences, and usability
}

This article was published in the following Dove Press journal:

Neuropsychiatric Disease and Treatment

\author{
Daniel Campos' \\ Adriana Mira ${ }^{1,2}$ \\ Juana Bretón-López ${ }^{1,3}$ \\ Diana Castilla ${ }^{1,3}$ \\ Cristina Botella ${ }^{1,3}$ \\ Rosa Maria Baños 3,4 \\ Soledad Quero ${ }^{1,3}$ \\ 'Department of Basic Psychology, \\ Universitat Jaume I, Castellón, \\ Spain; ${ }^{2}$ Department of Psychology \\ and Sociology, Facultad de Ciencias \\ Sociales y Humanas, Universidad \\ de Zaragoza, Campus Universitario \\ de Teruel, Teruel, Spain; ${ }^{3}$ CIBER de \\ Fisiopatología de la Obesidad y \\ Nutrición (CIBEROBN), Barcelona, \\ Spain; ${ }^{4}$ Department of Personality, \\ Evaluation and Psychological \\ Treatment, Universitat de València, \\ Valencia, Spain
}

Purpose: Internet-based treatments have been tested for several psychological disorders. However, few studies have directly assessed the acceptability of these self-applied interventions in terms of expectations, satisfaction, treatment preferences, and usability. Moreover, no studies provide this type of data on Internet-based treatment for flying phobia (FP), with or without therapist guidance. The aim of this study was to analyze the acceptability of an Internet-based treatment for FP (NO-FEAR Airlines) that includes exposure scenarios composed of images and real sounds. A secondary aim was to compare patients' acceptance of two ways of delivering this treatment (with or without therapist guidance).

Patients and methods: The sample included 46 participants from a randomized controlled trial who had received the self-applied intervention with $(n=23)$ or without $(n=23)$ therapist guidance. All participants completed an assessment protocol conducted online and by telephone at both pre- and posttreatment.

Results: Results showed good expectations, satisfaction, opinion, and usability, regardless of the presence of therapist guidance, including low aversiveness levels from before to after the intervention. However, participants generally preferred the therapist-supported condition.

Conclusion: NO-FEAR Airlines is a well-accepted Internet-based treatment that can help enhance the application of the exposure technique, improving patient acceptance and access to FP treatment.

Keywords: Internet-based exposure, expectations, satisfaction, treatment preferences, usability, flying phobia

\section{Introduction}

Internet- and computer-based treatments have been tested and can be considered evidence-based treatments for several psychological disorders. ${ }^{1-4}$ Specifically, for anxiety disorders (including panic, specific phobias, social anxiety disorder, and generalized anxiety disorder), Internet-based treatments have shown large effect sizes as compared to control groups (waiting list or placebo treatment) and equal or greater effects when compared to face-to-face treatment. ${ }^{5-8}$

Authors have pointed out that the use of the Internet to deliver psychological treatment can help address common mental health treatment barriers - specifically, in terms of access and geographical reach, versatility, safety, acceptability, and convenience. ${ }^{9-11}$ Focusing on the specific phobias, Internet-based treatments can help overcome the limitations of in vivo exposure, such as low acceptance by patients and
Correspondence: Soledad Quero Department of Basic Psychology, Universitat Jaume I, Av Vicente Sos Baynat s/n, 12006 Castellón, Spain

Tel +3496438764l

Email squero@uji.es 
therapists and the difficulties in accessing treatment outlined in several studies. ${ }^{12-14}$

The implementation of Internet-based interventions is promising, but some challenges remain. ${ }^{15,16}$ One important issue in research related to self-applied programs is acceptability. Although clinical effectiveness is important, the acceptability of Internet-based treatments is an additional criterion that is likely to affect their implementation. ${ }^{17}$ Acceptability refers to the degree to which patients (or other users) are satisfied or at ease with a service and willing to use it. $^{7,18}$ A treatment is acceptable when it is perceived as fair and reasonable, appropriate, and non-intrusive in addressing a problem. ${ }^{17,19}$ Following the recommendations of the United Kingdom technology appraisal of computerized treatments, evaluation of treatment acceptability must also be a priority. ${ }^{15}$ In fact, taking an intervention's acceptability into account can improve adherence ${ }^{20}$ and outcomes. ${ }^{21}$ Some variables related to treatment acceptability are expectations, satisfaction, treatment preferences, and usability. ${ }^{22-24}$ The literature suggests that "expectations" may be crucial to the psychotherapy process and its outcomes, ${ }^{25}$ and positive expectations have been associated with better outcomes. ${ }^{26,27}$ Moreover, "satisfaction" is another important variable because it provides information about the feasibility of the intervention, helping to optimize its effectiveness. ${ }^{26,28}$ Treatment "preferences" - the systems or interventions that are preferred by patients - are considered a way to enhance clinical utility, thereby increasing treatment

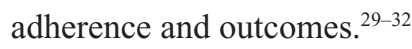

In spite of the importance of treatment acceptability, few studies have focused on its assessment in terms of Internetbased interventions, ${ }^{22-24,33,34}$ and most of them provide only indirect data. ${ }^{35,36}$ The most commonly used rating to measure acceptability is program adherence. ${ }^{26,37}$ Although this information about the completion rate is quite important, it is necessary to evaluate acceptability more directly, as Kaltenthaler et $\mathrm{al}^{15}$ concluded in their systematic review. With regard to "usability" testing, it has been described as a method for evaluating user performance and acceptance of a product during its development process. ${ }^{38}$ Results from usability studies can help us to enhance the technology developed. However, few studies have assessed usability or ease-of-use issues in Internet- and computer-based interventions. ${ }^{23,39-42}$ As Currie et $\mathrm{al}^{41}$ claimed research that tests user perceptions of usability in computerized mental health self-help programs is still in its infancy, in spite of their advances and advantages.

Studies on Internet-based treatments for specific phobias are scarce. The literature we reviewed reveal two small trials - one on spider phobia ${ }^{43}$ and another on snake phobia $^{44}$ - but the authors did not assess treatment acceptance. In a series of cases, Botella et $\mathrm{al}^{45}$ provided preliminary data on the acceptability of a self-applied telepsychology program using an intranet to treat small-animal phobia (spiders, cockroaches, and mice). In addition, Kok et al ${ }^{46}$ pointed out that an Internet-based exposure intervention with weekly support was well accepted in outpatients awaiting face-to-face psychotherapy for several phobias (including specific phobia), although a high dropout rate was observed (only 13.3\% finished the intervention). Furthermore, some interesting studies have been conducted in the area of online image-based exposure for spider fear, providing evidence in support of their efficacy. ${ }^{47}$ For example, Matthews et al ${ }^{48}$ found that alternating fear-relevant and -irrelevant exposure (continuous vs intermittent exposure) was feasible in online exposure and may lead to habituation with less summed anxiety that has implications for tolerability and acceptability. However, acceptability was not directly assessed throughout those studies. Recently, Schröder et $\mathrm{al}^{49}$ conducted a randomized controlled trial (RCT) of a transdiagnostic Internet intervention for individuals with panic and phobias, and they evaluated satisfaction with the program. Participants reported a moderate level of satisfaction. Furthermore, the authors pointed out that attitudes toward psychological online interventions moderated the effects of the program, as there was a substantial increase in benefits among patients with more positive attitudes.

With regard to flying phobia (FP), some computerassisted treatments have shown patient acceptance, but the Internet was not used to deliver them. ${ }^{30,50}$ Tortella-Feliu et a ${ }^{50}$ carried out a randomized trial comparing three computeraided exposure treatments for FP: virtual reality exposure treatment assisted by a therapist; computer-aided exposure with a therapist present throughout the exposure sessions; and self-administered computer-aided exposure. All three of the interventions were well accepted without compromising their efficacy. Based on data from Tortella-Feliu et al, ${ }^{50}$ BretónLópez et $\mathrm{l}^{30}$ pointed out that participants' preferences for the three interventions differed in terms of subjective effectiveness, recommendation to others, and aversiveness. According to the authors, "facing the flight situation in a more realistic way makes the participants judge the treatment as more aversive." ${ }^{30}$ In this regard, decreasing a treatment's aversiveness is a key feature and an ethical commitment in efforts to improve the application of the exposure technique. ${ }^{12-14}$ Thus, research on patients' acceptance of computer-assisted exposure using significant stimuli is especially relevant. 
Particularly in the case of FP, the application of exposure through interactive computer programs and Internet-based delivery is specifically recommended because it can produce lower aversion levels and reach more people in need.

Another relevant research issue that might be related to the acceptability of Internet-based treatments is the degree of support or guidance provided during the intervention process. ${ }^{51,52}$ Recently, a growing body of research has been conducted to determine the role of human support in these interventions, and the literature shows the importance of providing this support. ${ }^{53}$ Meta-analyses have shown that Internet- and computer-based treatments that offer some level of professional support or guidance produce larger effect sizes and lower dropout rates than self-help programs without any support. ${ }^{53,54}$ Patients generally reported greater satisfaction with therapist-supported Internet-based interventions; however, as explained earlier, patient satisfaction was not formally assessed. ${ }^{6}$ Other recent studies have found no significant differences in adherence between conditions with and without human support. ${ }^{55,56}$ Therefore, it is interesting to continue to investigate whether there are differences in acceptability, depending on the support provided.

To our knowledge, no studies have directly assessed these variables to determine the user acceptability of an Internetbased program for FP that includes exposure scenarios composed of images and real sounds. The aim of the present study is to examine the acceptability of NO-FEAR Airlines in terms of expectations, satisfaction, treatment preferences, and usability. A secondary aim is to explore patient acceptance of two ways of delivering the program - with and without therapist guidance.

\section{Patients and methods Research design}

This study employed a randomized control design where the participants were randomly allocated to three groups: ${ }^{57} 1$ ) Internet-based exposure treatment for FP without therapist guidance (NO-FEAR Airlines completely self-applied); 2) Internet-based exposure treatment for FP with therapist guidance (brief, weekly call; NO-FEAR Airlines with therapist guidance); and 3) a waiting-list control. In the present study, data from participants allocated to the two treatment conditions were analyzed. The RCT was regis-

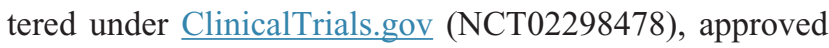
by the Ethics Committee of Universitat Jaume I (Castellón, Spain, December 20, 2014), and conducted in compliance with the study protocol, the Declaration of Helsinki, the CONSORT statements (http://www.consort-statement.org),
CONSORT-EHEALTH guidelines, ${ }^{58}$ and good clinical practice guidelines.

\section{Participants}

The final sample included in this study comprised 46 participants (NO-FEAR Airlines completely self-applied, $\mathrm{n}=23$; NO-FEAR Airlines with therapist guidance, $n=23$ ). Of the total sample, 32 participants were women and 14 were men. The mean age was 37.59 years $(\mathrm{SD}=11.13)$, ranging from 20 to 65 years. Most of the participants had completed a university degree $(80.4 \%)$ or secondary studies $(19.6 \%)$. With regard to marital status, $50 \%$ were married, $45.7 \%$ single, and $4.3 \%$ separated or divorced. Most of the sample were employed (58.7\%), 17.4\% were students, 17.4\% were unemployed, and $6.5 \%$ were retired. Participants came from Spain (89\%), Colombia (4.3\%), the USA (2.2\%), Cuba (2.2\%), and Italy $(2.2 \%)$. With regard to pharmacological treatment, $93.5 \%$ of the participants were not taking any regular medication, and $6.5 \%$ of the sample were receiving anxiolytics for anxietyrelated symptoms.

\section{Recruitment and procedure}

Recruitment was carried out online using both professional websites (ie, LinkedIn) and non-professional social networks (ie, Facebook and twitter), as well as advertisements in newspapers and posters placed in local universities. People who were interested could request participation through the research website (www.fobiavolar.es) and by signing the informed consent form. All participants were contacted by telephone to screen them for the inclusion and exclusion criteria and to explain the research terms. Participants who met the study criteria received a diagnostic telephonic interview, and were randomly assigned to one of the three experimental groups using a computer randomization program (Epidat 4.0) run by an independent researcher who was blinded to the characteristics of the study. Before starting the treatment, participants allocated to the two treatment conditions (completely self-applied or self-applied with therapist guidance) received a brief explanation of the rationale for the treatment, how to use the program, and information of each experimental condition (including details about how both conditions - with and without therapist guidance - work), but information about which condition they would receive was not provided at this stage. Thereafter, participants reported their preferences without knowing the treatment to which they had been assigned. Next, researchers told patients the condition to which they had been randomly allocated, and they assessed their expectations about 
the treatment. Posttreatment, participants reported their satisfaction, their preferences, and the usability of the program. A detailed description of the recruitment process and procedure is provided in the study protocol. ${ }^{57}$

\section{Inclusion and exclusion criteria}

The inclusion criteria were: adults who were 18 years of age or older and met the Diagnostic and Statistical Manual for Mental Health Disorders-Fifth edition (DSM-5) $)^{59}$ criteria for specific, situational phobia (FP); sufficient knowledge to understand and read Spanish; the ability to use a computer; and access to the Internet. Exclusion criteria were: receiving psychological treatment for FP; diagnosis of a severe mental disorder (abuse or dependence on alcohol or other substances, psychotic disorder, dementia, or bipolar disorder); presence of depressive symptomatology, suicidal ideation or plan; presence of heart disease; pregnancy (from the fourth month). Participants with comorbid and related disorders (ie, panic disorder, agoraphobia, claustrophobia, or acrophobia) were included when FP was the primary diagnosis. Receiving pharmacological treatment was not an exclusion criterion during the study period, but any increase and/or change in the medication implied the participant's exclusion from the study. A decrease in pharmacological treatment was accepted.

\section{Measures}

\section{Diagnostic interview}

Anxiety Disorders Interview Schedule for DSM-IV-TR $(A D I S-I V)$ is a semi-structured interview used to determine the diagnostic status and quantify different features related to the phobia (on a scale from 0 to 8 ). The section on specific phobias was used in this study. This interview has been validated in Spanish and shows adequate psychometric properties. ${ }^{60-62}$

\section{Treatment Preferences Questionnaire}

The Treatment Preferences Questionnaire was specifically developed for this research. ${ }^{57}$ This instrument is composed of five questions designed to measure participant preferences for the two treatment conditions included in the study (with and without therapist support): 1) "Preference" ("If you could have chosen between the two treatments, which one would you have chosen?"); 2) "Subjective effectiveness" ("Which of these two treatments do you think would have been the most effective in helping you to overcome your problem?"); 3) "Logic" (Which of these two treatments do you think would have been the most logical to help you overcome your problem); 4) "Subjective aversion" ("Which of these two treatments do you think would have been the most aversive?"); and 5) "Recommendation" ("Which of these two treatments would you recommend to a friend with the same problem you have?"). Questions have two response options based on the two treatment conditions.

\section{Treatment expectations and satisfaction scales}

These questionnaires were adapted from Borkovec and $\mathrm{Nau}^{63}$ to measure participant expectations before treatment and their later satisfaction with it. Each scale includes six items rated from 0 ("not at all") to 10 ("very much"). The questions addressed how logical the treatment seemed, to what extent the patient expected to be satisfied with it, whether the patient would recommend the treatment to others, whether it would be useful in treating other problems, the treatment's usefulness for the patient's problem, and to what extent it could be aversive. This adaptation has been used in several studies. ${ }^{22-24,50,64}$

\section{Qualitative Interview}

A Qualitative Interview was also specifically developed to assess participant opinions about the NO-FEAR Airlines program and the support received. This interview included 10 questions: nine of them regarding usefulness of exposure scenarios, fixed pictures, sounds, psychoeducation, overlearning, and the opinion about receiving support or not rated on a scale from 1 to 5 ( 1 = very little; $2=$ little; 3 = something; $4=$ a lot; and $5=$ very much) and one dichotomous question ("yes" or "no") regarding whether they would like having at their disposal the program for more time after the treatment has finished. Additionally, options to extend the participants' qualitative responses were available.

\section{Usability and Acceptability Questionnaire}

This instrument was adapted from the System Usability Scale (SUS) in order to assess the usability of a service or product and the acceptance of technology by the people who use it. ${ }^{65,66}$ The SUS has been shown to be a valuable and robust tool for assessing the quality of a wide range of user interfaces, as it is easy to use and understand. ${ }^{23,65}$ This scale includes 10 statements rated on a five-point scale measuring agreement with the statement ( $0=$ strongly disagree; $4=$ strongly agree). The final score is obtained by adding the scores on each item and multiplying the result by 2.5 . Scores range from 0 to 100 , where higher scores indicate better usability, according to Bangor et $\mathrm{a}^{65,67}$ (Figure 1). Figure 1 shows the mapping of the SUS adjective ratings scale (from "Worst imaginable" to "Best imaginable") corresponding to acceptability ranges (from "Not acceptable" to "Acceptable"), and quartiles range (from the first to fourth quartile). We replaced the 


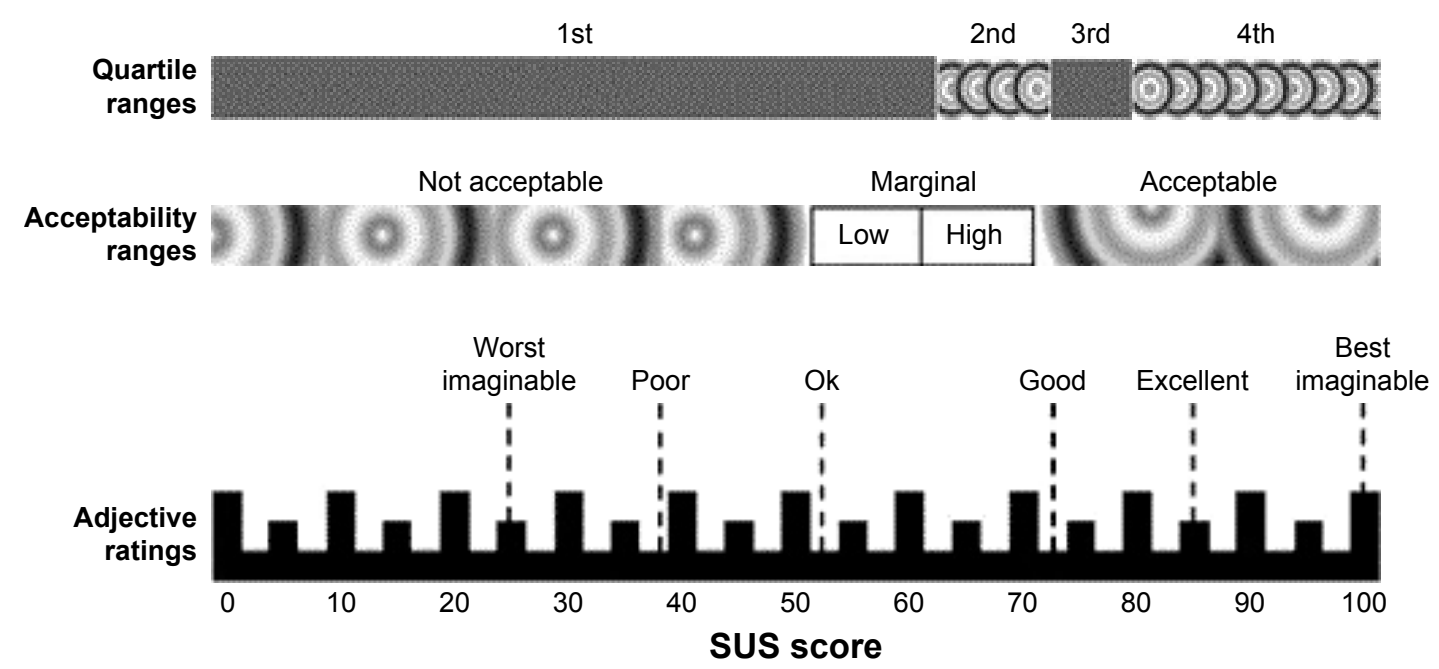

Figure I A comparison of mean SUS scores by quartile, adjective ratings, and the acceptability of the overall SUS score. Note: Data from Bangor et al..$^{65,67}$

Abbreviation: SUS, System Usability Scale.

word "system" with "NO-FEAR Airlines," and we adapted some items to assess: learnability, capacity to use, orientation, effectiveness, ecological model, ease of instructions, visibility, intention to use, utility, and ease of use. The Usability and Acceptability Questionnaire is currently being validated by our research group, and a short form consisting of seven items was used in a previous study, showing a Cronbach's alpha of $0.94 .^{40}$

\section{Treatment program}

NO-FEAR Airlines is an Internet-based exposure treatment for FP. This program was designed to be completely selfapplied over the Internet, and it allows people who are afraid of flying to be exposed to images and sounds related to their phobic fears on a standard personal computer. From a clinical point of view, NO-FEAR Airlines is based on a previous program - Computer Assisted Fear of Flight Treatment (CAFFT) ${ }^{50,68}$ NO-FEAR Airlines was designed with linear navigation (Figure 2) - that is, the patient can only continue on to the next section. This design helps to optimize the treatment structure (assessment, psychoeducation, exposure, and overlearning). The graphical user interface includes visual flying metaphors in order to improve immersion and the sense of presence in the exposure scenarios.

The program includes both an "assessment protocol" and a "treatment protocol". The "treatment protocol" has three therapeutic components: psychoeducation, exposure, and overlearning. "Psychoeducation" consists of information about what the program will contain, as well as specific information related to FP using text, vignettes, and illustrations, in order to make the therapeutic content more attractive to the patient.
The "Exposure" component is provided through six scenarios composed of significant stimuli such as images and real sounds related to the flight process: 1) flight preparation; 2) airport; 3) boarding and taking off; 4) the central part of the flight; 5) the airplane's descent, approach to the runway, and landing; and 6) sequences with images and auditory stimuli related to plane crashes. Exposure presents the different scenarios, depending on the patient's anxiety level recorded in the assessment (based on the FFQ-II questionnaire scores). ${ }^{69}$ Therefore, the system reacts in real time to the exposure needs of each patient, organizing the scenes from low to high anxiety. "Overlearning" is offered as additional exposure (to each scenario). Patients can choose the scenarios they want to face based on their needs, with a higher degree of difficulty when storm conditions and turbulence are simulated. The length of the treatment depends on each patient's pace. Patients were advised to carry out approximately two exposure scenarios per week, taking a few days off between sessions, although each participant was free to advance at his/her own pace within a maximum period of 6 weeks. A detailed description of NO-FEAR Airlines can be found in the published literature. ${ }^{57,70}$

The program described earlier was delivered in two formats: 1) NO-FEAR Airlines completely self-applied participants self-administered the Internet-based treatment, and only automatic support was provided by the program; technical assistance (ie, web-accessibility problems or forgotten password) was provided if necessary. 2) NO-FEAR Airlines with therapist guidance - in this case, participants self-applied the treatment over the Internet and received minimal therapist support consisting of a brief weekly phone 


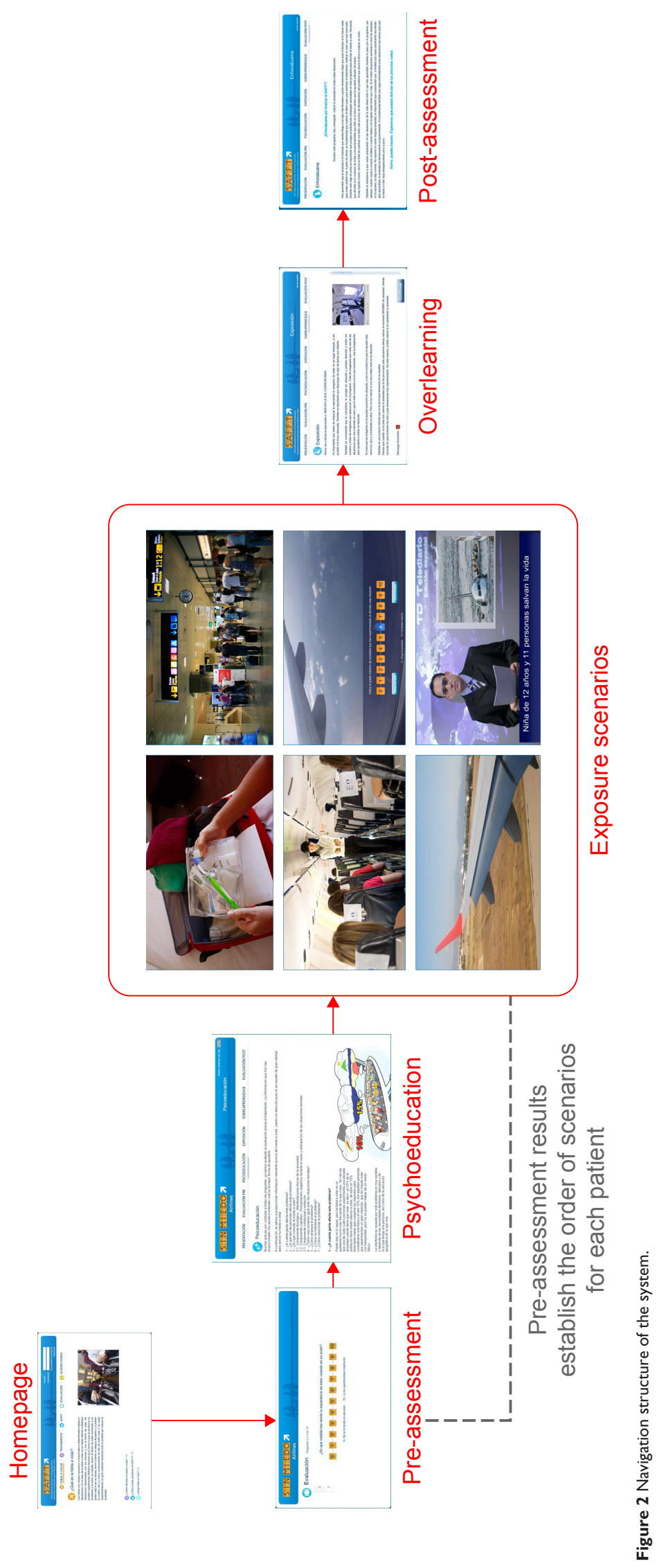


call (maximum $5 \mathrm{~min}$ ) to assess and guide the participant's progress by providing feedback and reinforcement until she/he had finished the treatment. In addition, the therapist checked for any problems and reminded the participant about the recommended treatment pace. Guidance content was standardized, although it could be tailored to patients' needs. However, support calls had no additional clinical content. Telephonic support was provided by trained and experienced psychologists.

\section{Statistics and data analysis}

Sociodemographic and participant data were examined by applying chi-square $\left(\chi^{2}\right)$ tests for categorical variables and Student's $t$-tests for continuous data. Group differences were studied using $\chi^{2}$ tests for participant preference patterns and multivariate analysis of variance (MANOVA) for expectations, satisfaction, usability, and the quantitative statements from the opinion interview. Separate MANOVAs were applied for each of the outcome measures mentioned, where all items were entered into the MANOVA as dependent variables and with the experimental group as a fixed factor (independent variable). In addition, a MANOVA was conducted to analyze whether significant changes were yielded between expectations (at pre-) and satisfaction (at post-intervention). The main effect of time as well as the interaction effect (time by group) were included in the statistical analysis. For the opinion interview, the proportion of participants who rated a score of 4 or 5 for questions on usefulness of exposure scenarios, fixed pictures, sounds, psychoeducation, and overlearning were calculated, and the differences between groups were compared using the $\chi^{2}$ test. Comparisons between the usefulness of the components of exposure scenarios reported by participants were assessed using paired sample $t$-tests. With regard to the Usability and Acceptability Questionnaire, the proportion of agreement with the statements (participants who rated a score of 3 or 4) was also calculated and $\chi^{2}$ tests to compare differences in proportions between groups were used. Finally, the SUS adjective ratings scale (from "Worst imaginable" to "Best imaginable") was used to provide a qualitative comparison of usability scores (Figure 1). ${ }^{65-67}$ All statistical analyses were conducted using IBM SPSS Statistics for Windows, version 23.

\section{Results}

\section{Sociodemographic and participant data}

Sociodemographic and participant data are presented in Table 1. No statistical differences were found between conditions (NO-FEAR Airlines completely self-applied vs
Table I Sociodemographic and participant data

\begin{tabular}{|c|c|c|}
\hline $\begin{array}{l}\text { Sociodemographic } \\
\text { variables }\end{array}$ & $\begin{array}{l}\text { NO-FEAR Airlines } \\
\text { completely self- } \\
\text { applied }(\mathbf{N}=\mathbf{2 3})\end{array}$ & $\begin{array}{l}\text { NO-FEAR Airlines self- } \\
\text { applied with therapist } \\
\text { guidance }(\mathbf{N}=\mathbf{2 3})\end{array}$ \\
\hline Age years & $36.30(8.14)$ & $38.87(13.56)$ \\
\hline \multicolumn{3}{|l|}{ Sex } \\
\hline Male & $8(30.8 \%)$ & $6(26.1 \%)$ \\
\hline Female & 15 (65.2\%) & 17 (73.9\%) \\
\hline \multicolumn{3}{|l|}{ Marital status } \\
\hline Married & $12(52.2 \%)$ & II (47.8\%) \\
\hline Single & $10(43.5 \%)$ & II (47.8\%) \\
\hline Divorced & I (4.3\%) & I (4.3\%) \\
\hline \multicolumn{3}{|l|}{ Educational level } \\
\hline Secondary school & $2(8.7 \%)$ & 7 (30.4\%) \\
\hline University education & 21 (9l.3\%) & $16(69.6 \%)$ \\
\hline \multicolumn{3}{|c|}{ Occupation } \\
\hline Student & $4(17.4 \%)$ & $4(17.4 \%)$ \\
\hline Unemployed & $4(17.4 \%)$ & $4(17.4 \%)$ \\
\hline Employed & $15(65.2 \%)$ & $12(52.2 \%)$ \\
\hline Retired & $0(\%)$ & $3(13.0 \%)$ \\
\hline \multicolumn{3}{|l|}{ Medication } \\
\hline Yes & I (4.3) & $2(8.7 \%)$ \\
\hline No & $22(95.7 \%)$ & 21 (91.3\%) \\
\hline
\end{tabular}

Notes: Mean (SD) are presented for age. There are no significant between-group differences.

NO-FEAR Airlines self-applied with therapist guidance) with regard to demographic data and medication-intake patterns.

\section{Attrition and adherence}

Forty-six participants started the program and completed the pretreatment assessment. From the total sample, 13 participants $(28.26 \%)$ withdrew from the program: six in the NOFEAR Airlines completely self-applied condition (13.04\%) and seven in the NO-FEAR Airlines self-applied with therapist support condition (15.22\%). No significant differences in attrition rates were found between the treatment conditions. Dropout reasons were reported as follows: own illness $(\mathrm{N}=1)$, partner illness $(\mathrm{N}=1)$, exposure scenarios did not evoke anxiety $(\mathrm{N}=1)$, lack of time $(\mathrm{N}=1)$, and unable to contact them $(\mathrm{N}=9)$. At the posttreatment assessment, the data on treatment acceptance were obtained from 33 participants (NO-FEAR Airlines completely self-applied, $\mathrm{n}=17$; NO-FEAR Airlines self-applied with therapist guidance, $\mathrm{n}=16$ ).

\section{Preferences}

Results of $\chi^{2}$ tests revealed significant differences between treatment conditions on all preference measures, except "aversiveness" at baseline and posttreatment. Before treatment, most participants (71.7\%) preferred the self-applied 
condition with therapist guidance $\left(\chi^{2}=8.70 ; p<0.01\right)$, $87 \%$ considered it more effective than the completely self-applied condition $\left(\chi^{2}=25.13 ; p<0.001\right), 82.6 \%$ of participants reported the therapist-supported condition as being more logical $\left(\chi^{2}=19.57 ; p<0.001\right)$, and $82.6 \%$ of participants would recommend it to a friend who had the same problem $\left(\chi^{2}=19.57 ; p<0.001\right)$. In addition, the completely self-applied condition was considered more aversive by $60.9 \%$ of participants, although statistically significant differences were not found.

Posttreatment, $72.7 \%$ of participants continued to prefer the self-applied treatment with therapist guidance $\left(\chi^{2}=6.82\right.$; $p<0.01), 84.8 \%$ considered it more effective $\left(\chi^{2}=16.03\right.$; $p<0.001), 90.9 \%$ assessed this condition as more logical $\left(\chi^{2}=22.09 ; p<0.001\right)$, and $87.9 \%$ would recommend it to a friend who had the same problem $\left(\chi^{2}=18.95 ; p<0.001\right)$. With regard to aversiveness, $54.5 \%$ of participants chose the completely self-applied program as the most aversive condition $\left(\chi^{2}=0.273 ; p=0.602\right)$, but no significant differences were reported between groups.

\section{Expectations and satisfaction}

As Table 2 shows, results from analyzing participant expectations and satisfaction with the Internet-based program

Table 2 Expectations and satisfaction scores

\begin{tabular}{|c|c|c|}
\hline \multirow{2}{*}{$\begin{array}{l}\text { Statements } \\
\text { and groups }\end{array}$} & \multirow{2}{*}{$\frac{\text { Expectations }}{\text { Mean (SD) }}$} & \multirow{2}{*}{$\frac{\text { Satisfaction }}{\text { Mean (SD) }}$} \\
\hline & & \\
\hline \multicolumn{3}{|l|}{ I. Logical } \\
\hline NFA & $8.17(1.23)$ & $8.12(1.54)$ \\
\hline $\mathrm{NFA}+\mathrm{TG}$ & $8.48(\mathrm{I} .4 \mathrm{I})$ & $7.75(1.91)$ \\
\hline Total sample & $8.33(1.32)$ & 7.94 (I.7I) \\
\hline \multicolumn{3}{|c|}{ 2. Satisfaction with the Internet-based program } \\
\hline NFA & $8.40(1.75)$ & $7.35(1.97)$ \\
\hline $\mathrm{NFA}+\mathrm{TG}$ & $8.87(1.46)$ & $7.06(1.98)$ \\
\hline Total sample & $8.63(1.6 I)$ & $7.21(1.95)$ \\
\hline \multicolumn{3}{|c|}{ 3. Recommend to others } \\
\hline NFA & $8.74(1.36)$ & $8.18(1.98)$ \\
\hline $\mathrm{NFA}+\mathrm{TG}$ & $8.74(1.42)$ & $8.31(2.08)$ \\
\hline Total sample & $8.74(1.37)$ & $8.24(2.00)$ \\
\hline \multicolumn{3}{|c|}{ 4. Usefulness for treating other psychological problems } \\
\hline NFA & $7.00(1.98)$ & $6.82(2.13)$ \\
\hline $\mathrm{NFA}+\mathrm{TG}$ & $7.70(2.14)$ & $6.56(2.30)$ \\
\hline Total sample & $7.34(2.07)$ & $6.69(2.19)$ \\
\hline \multicolumn{3}{|c|}{ 5. Usefulness for treating their problem } \\
\hline NFA & $7.74(I .7 I)$ & $7.24(2.05)$ \\
\hline $\mathrm{NFA}+\mathrm{TG}$ & $8.26(2.00)$ & $6.75(3.04)$ \\
\hline Total sample & $8.00(1.86)$ & $7.00(2.55)$ \\
\hline \multicolumn{3}{|l|}{ 6. Aversiveness } \\
\hline NFA & $2.6 I(3.26)$ & $2.35(2.67)$ \\
\hline $\mathrm{NFA}+\mathrm{TG}$ & $2.35(2.98)$ & $1.75(2.11)$ \\
\hline Total sample & $2.48(3.10)$ & $2.06(2.39)$ \\
\hline
\end{tabular}

Note: There are no significant between-group differences.

Abbreviations: NFA, NO-FEAR Airlines completely self-applied; NFA + TG, NO-FEAR Airlines self-applied with therapist guidance. revealed high scores on all expectations and satisfaction measures, except "aversiveness" - which obtained low scores. MANOVA analysis did not reveal significant differences between the two ways of delivering the treatment on any of the expectations and satisfaction measures. In addition, results showed a statistically significant reduction between scores at pre- (that refer to expectations) and post-intervention (satisfaction scale; $\mathrm{F}[6,26]=2.875 ; p<0.05$ ), specifically for the items that referred to "satisfaction with the intervention" $(\mathrm{F}[1,31]=2.796 ; p<0.05)$ and "usefulness for treating their problem" $(\mathrm{F}[1,31]=5.908 ; p<0.05)$. Nevertheless, no significant interaction effect was found.

\section{Opinion interview}

Results from the opinion interview revealed that the "exposure scenarios" were assessed as useful (mean 3.48, SD 0.91). All program components were valued as helpful, and no statistical differences were found between treatment conditions. Specifically, the proportion of participants who rated scores of 4 or 5 (on a scale ranging from 1 "very little" to 5 "very much") for the question that referred to the usefulness was $69.57 \%$ for exposure scenarios, $50 \%$ for fixed pictures, $89.13 \%$ for sounds, $65.21 \%$ for psychoeducation component, and $73.9 \%$ for overlearning. No statistically significant differences were found for proportions of participants reporting values of 4 or 5 between both experimental groups.

With regard to the comparison between components of exposure scenarios, the "sounds" of each scenario were considered significantly more useful than the fixed images ( $p<0.001)$, psychoeducation $(p<0.01)$, and overlearning component $(p<0.001$; Table 3$)$. Moreover, fixed images were

Table 3 Opinion interview

\begin{tabular}{|c|c|c|c|}
\hline Statement & $\begin{array}{l}\text { NO-FEAR } \\
\text { Airlines } \\
\text { completely } \\
\text { self-applied }\end{array}$ & $\begin{array}{l}\text { NO-FEAR Airlines } \\
\text { self-applied with } \\
\text { therapist guidance }\end{array}$ & $\begin{array}{l}\text { Total } \\
\text { sample }\end{array}$ \\
\hline $\begin{array}{l}\text { I. Exposure scenarios } \\
\text { usefulness }\end{array}$ & $3.53(0.72)$ & $3.44(1.09)$ & $3.48(0.91)$ \\
\hline $\begin{array}{l}\text { 2. Fixed pictures' } \\
\text { usefulness }\end{array}$ & $2.82(1.07)$ & $3.25(1.13)$ & $3.03(1.10)$ \\
\hline 3. Sounds' usefulness & $4.53(0.62)$ & $4.18(0.98)$ & $4.36(0.82)$ \\
\hline $\begin{array}{l}\text { 4. Psychoeducation } \\
\text { component's usefulness }\end{array}$ & $3.76(1.15)$ & $3.56(1.15)$ & $3.67(1.14)$ \\
\hline 5. Overlearning usefulness & $3.47(1.28)$ & $3.88(1.09)$ & $3.67(1.19)$ \\
\hline $\begin{array}{l}\text { 6. Would you like to have } \\
\text { access to the program } \\
\text { to use it in the future? }\end{array}$ & & & \\
\hline Yes & $76.5 \%$ & $68.8 \%$ & $72.9 \%$ \\
\hline No & $23.5 \%$ & $31.3 \%$ & $27.3 \%$ \\
\hline
\end{tabular}

Notes: Mean (SD) are presented. There are no significant between-group differences. 
Table 4 Usability and Acceptability Questionnaire

\begin{tabular}{|c|c|c|c|c|}
\hline Statement & $\begin{array}{l}\text { NO-FEAR Airlines } \\
\text { completely } \\
\text { self-applied }\end{array}$ & $\begin{array}{l}\text { NO-FEAR Airlines } \\
\text { self-applied with } \\
\text { therapist guidance }\end{array}$ & $\begin{array}{l}\text { Total } \\
\text { sample }\end{array}$ & $\%(3$ or 4$)$ \\
\hline I. People could learn to use NO-FEAR Airlines quickly & $3.71(0.47)$ & $3.63(0.8 I)$ & $3.67(0.65)$ & 97.82 \\
\hline 2. I felt confident using NO-FEAR Airlines & $3.82(0.39)$ & $3.75(0.44)$ & $3.79(0.42)$ & 100 \\
\hline 3. Generally, I knew what I had to do at all times & $3.59(0.62)$ & $3.87(0.34)$ & $3.73(0.52)$ & 97.82 \\
\hline $\begin{array}{l}\text { 4. Once I had learned how to use NO-FEAR Airlines, I could do } \\
\text { the tasks quickly }\end{array}$ & $3.71(0.99)$ & $3.25(1.48)$ & $3.49(1.25)$ & 91.30 \\
\hline 5. NO-FEAR Airlines could be used anywhere and in any context & $2.88(1.17)$ & $2.56(1.50)$ & $2.72(1.33)$ & 73.91 \\
\hline 6. NO-FEAR Airlines' instructions are easy to follow & $3.53(1.01)$ & $3.81(0.40)$ & $3.67(0.77)$ & 97.82 \\
\hline 7. Font size and row button size are sufficient for me & $3.71(0.99)$ & $3.81(0.40)$ & $3.76(0.75)$ & 97.82 \\
\hline 8. I would like to use this system frequently & $3.10(1.03)$ & $2.88(1.15)$ & $2.97(1.09)$ & 78.26 \\
\hline 9. Overall, I think NO-FEAR Airlines is quite useful to me & $2.88(0.93)$ & $3.00(1.26)$ & $2.94(1.09)$ & 82.61 \\
\hline 10. Overall, I think NO-FEAR Airlines is easy to use & $3.88(0.33)$ & $3.81(0.40)$ & $3.85(0.36)$ & 100 \\
\hline Overall score & 86.91 (10.73) & 85.94 (II.2I) & $86.44(10.8 I)$ & \\
\hline
\end{tabular}

Notes: Mean (SD) are presented; ( 3 or 4$)$ = proportion of participants from the total sample who rated a score of 3 or 4 on each statement. There are no significant between-group differences.

considered significantly less useful than psychoeducation $(p<0.05)$ and overlearning components $(p<0.05)$. Qualitative opinions of some participants pointed out that they would prefer navigable images such as $360^{\circ}$ view images or short videos with movement images. In addition, $72.7 \%$ of participants would like to have access to the program after completing the treatment for the first time, in order to use it in the future and go over it between flights.

Finally, with regard to the opinion about receiving support or not, participants who received the "weekly therapist guidance" pointed out that they liked it (mean 4.56, SD 0.81) and considered it "useful" (mean 4.25, SD 1.06), expressing a positive opinion ranging from "a lot" and "to very much". Participants allocated to the completely self-applied condition said they would have liked to receive therapist support and rated it as helpful between "something" and "very much" (mean 3.35, SD 1.45; mean 3.11, SD 1.36, respectively).

\section{Usability and Acceptability}

Usability and Acceptability scores are shown in Table 4. According to Bangor et al, ${ }^{67}$ their results revealed that NO-FEAR Airlines showed high acceptability levels among participants, and it was classified as "excellent" on the Usability Adjective Rating Scale (Figure 1). The MANOVA analysis did not reveal statistical differences between groups $(\mathrm{F}[10,22]=0.986 ; p=0.483)$. The proportion of participants from the total sample who gave a rating of 3 or 4 (on a scale ranging from 0 "strongly disagree" to 4 "strongly agree") is displayed in Table 4. Overall, values ranged from $73.91 \%$ to $100 \%$. Moreover, $\chi^{2}$ tests did not reveal statistically significant differences on proportion of agreement (on who rated 3 or 4 ) between both of the experimental groups.

\section{Discussion}

The present study aimed to analyze the acceptability of an Internet-based treatment for FP (NO-FEAR Airlines) that includes exposure scenarios composed of images and real sounds. A secondary aim was to compare patient acceptance of two methods of delivering this self-applied treatment (completely self-applied or self-applied with therapist guidance). On the one hand, results for "adherence" showed that most of the participants completed the online intervention (71.24\%). Thus, the dropout rate was in line with other studies that used the Internet to deliver psychological treatment $(\sim 30 \%){ }^{71-73}$ Nevertheless, this result contrasts with Kok et al, ${ }^{46}$ who found a high attrition rate in treatments for phobic outpatients. On the other hand, no differences in adherence were found in the present study when considering therapist guidance. Data on the impact of support on adherence to Internet-based interventions is inconsistent and varies across studies. ${ }^{53-56,74-76}$

With regard to treatment "preferences" assessed at pre- and post-intervention stages, results indicated that participants generally preferred the self-applied condition with therapist guidance. They considered this treatment condition to be more effective and more logical, and they would recommend it more than the completely self-applied condition, although no differences were found when aversiveness was considered. These results suggest that therapist guidance was not relevant in deciding which condition they would prefer in terms of aversiveness, but it clearly affected patient preferences overall. These findings are congruent with studies that recommend the need to offer support, guidance, and reinforcement to the participant during exposure in self-applied treatments, and this support has been related to patient preferences. ${ }^{30}$ 
It is interesting that, in this study, the therapist's guidance did not include clinical content, which is linked to the important issue of who is providing the support and what kind of guidance is required. Although few studies have been carried out on acceptability variables, the literature suggests that the qualifications of the people providing the guidance (technicians vs clinicians) might not be very important. ${ }^{77}$ Generally, authors suggest that, depending on the degree of structure of the Internet intervention model adopted, guidance can be mainly practical and supportive - based on reinforcement, rather than explicitly therapeutic content. ${ }^{9}$ Thus, guidance could be provided through automated reinforcement and persuasive technologies. ${ }^{55,75}$ This idea agrees with authors who indicate that unguided Internet-based interventions can work similarly with automated guidance and no human support. ${ }^{56,78-81}$ Therefore, we suggest that including automated guidance and making patients aware of it could help to reduce these differences in preferences for Internet interventions delivered with or without therapist guidance.

In contrast, participants in both groups reported high "expectations" and "satisfaction" scores, including low aversiveness levels toward the Internet-based exposure both before and after the treatment. These results coincide with previous studies showing that computer-assisted treatments are well accepted, in terms of expectations and satisfaction to treat FP. ${ }^{50,68}$ In addition, they are consistent with studies conducted with Internet-based interventions for specific phobias and other anxiety disorders, where participants also reported positive expectations and high satisfaction. ${ }^{2,22,45,81}$ It is true that patient satisfaction has generally been found to be higher in therapist-supported, Internet-based interventions. ${ }^{6}$ However, coinciding with our results, other studies have found that providing therapist support does not affect satisfaction. ${ }^{56,82}$ In addition, the data on aversiveness are especially relevant. As pointed out earlier, participants in both intervention groups reported low aversiveness levels toward the Internet-based exposure intervention in the evaluation of both expectations and satisfaction. Moreover, no differences were found in treatment preferences related to aversiveness, and the number of participants who preferred the supported intervention diminished after treatment. This is important because reducing aversion is a major challenge in exposure treatment for phobias. ${ }^{12-14}$ These results suggest that NO-FEAR Airlines self-applied with and without therapist guidance - could help improve the exposure technique's acceptance due to its reduced exposure aversiveness. According to Botella et al, ${ }^{22}$ Internet-delivered treatments may be particularly valuable to patients who are reluctant to start an in vivo exposure intervention because they provide a less frightening way to confront their fears. Moreover, it is interesting to note that scores on satisfaction scale (assessed at posttreatment) were lower than expectations (assessed at pretreatment) on several items, revealing significant reductions for the items that referred to satisfaction with the intervention and usefulness for treating their problem. No significant interaction effect was found, indicating that reductions were similar in both groups. In spite of such significant decrements on satisfaction items, it is worth considering that mean scores were still high, revealing good participant opinion, and the differences found could be caused by the initial high expectations. Additional explanations are twofold: First, participants were volunteers that could be especially interested in receiving an Internet-based treatment, thus inflating expectation scores. Second, participants could have experienced some anxiety levels during the treatment and exposure scenarios that may affect the decrement in satisfaction scores. Thus, anxiety experienced during the treatment may have had an influence on satisfaction reported after treatment. Further research is required to confirm these hypotheses.

With regard to the results obtained from the "opinion interview", all the program components (ie, psychoeducation, exposure, and overlearning) were accepted and found to be useful by the participants, agreeing with studies using computer-assisted treatment for FP. ${ }^{68}$ Focusing particularly on the features of exposure scenarios, sounds were rated as more useful than fixed pictures. These data are consistent with previous findings that highlight the critical role of sound in evoking anxiety in patients with FP. ${ }^{50,83}$ In addition, some participants suggested the inclusion of navigable images, such as $360^{\circ}$ pictures, or short videos with movement images in order to improve the scenarios and evoke a greater sense of presence. This issue addresses an interesting question related to improving exposure by creating more realistic exposure scenarios. However, according to Tortella-Feliu et al, ${ }^{50}$ literature has shown that treatment effects are not enhanced by enriching computer-generated exposure environments or creating more sophisticated immersive conditions. ${ }^{83-85}$ Moreover, some authors have suggested that, particularly referring to the flight situation, facing the feared situation in a more realistic way may evoke higher aversiveness levels, ${ }^{30}$ which could hinder the treatment's acceptability. However, more research is needed on this topic.

Finally, "usability" results would place NO-FEAR Airlines between the third and fourth quartile, achieving the "excellent" rating on the Usability Adjective Rating Scale in both the intervention conditions and showing that receiving therapist 
guidance did not affect the system's usability. Based on the technology acceptance model, authors have suggested that one of the factors that can be related to the intention to use a product in the future is ease of use. ${ }^{86-89}$ Therefore, efforts to research and ensure the usability of Internet-based treatments might lead more people to accept the Internet to treat their psychological problems, continue to use it in the future, and recommend it to friends and family. Thus, an important challenge in psychological treatments is improved - that is, their dissemination. ${ }^{90}$

In summary, our results showed that NO-FEAR Airlines was well accepted among participants, with no differences when considering therapist guidance, in terms of attrition rates, expectations, satisfaction, opinions, and usability. However, participants preferred the self-applied condition with therapist guidance. Therefore, our results partially agree with studies that highlighted the role of therapist guidance to enhance treatment acceptability. ${ }^{6}$ According to our findings, we suggest these inconsistencies could point out that the role of therapist guidance has different implications, depending on the disorder involved. Thus, in specific phobias - specifically in FP - therapist guidance might not seem to be relevant in improving treatment acceptability, particularly with regard to attrition rates, expectations, satisfaction, opinion, and usability. A further explanation could be related to the fact that all participants were contacted by a therapist at both the pre- and posttreatment stages to explain the research criteria and design as well as to conduct the subsequent assessments. Studies have found that providing initial human contact enhances the treatment. ${ }^{91}$ Nevertheless, based on our data, therapist guidance affects treatment preferences. More research is needed to formally assess the acceptability of Internet-based treatments, depending on the support provided.

In conclusion, together, our results highlight good acceptability of NO-FEAR Airlines by patients for the treatment of FP, when completely self-applied and self-applied with therapist guidance. However, the present study presents some limitations that should be mentioned. First, assessments were conducted online and via phone calls. Some authors suggest that psychometric properties may change when the assessment is conducted via the web, ${ }^{92}$ although several studies have shown the usefulness of Internet- and telephonically administered assessments and their concordance with traditional face-to-face assessment. ${ }^{93-96}$ Second, another limitation to consider is that participants voluntarily requested online access to the study. Thus, people who wanted to participate might be especially interested in receiving a treatment delivered via the Internet and more likely to accept the program by expressing a favorable opinion. Future research might examine these issues in other contexts (ie, primary care). Another interesting issue that has not been considered in this study refers to the possible influence of the technical support provided, which was available for both experimental conditions. The number of participants receiving technical support by phone was not recorded in our trial; thus, the differences in patterns of use could not be analyzed. Finally, usability assessment was based on one questionnaire rather than on qualitative feedback that might indicate overall program impressions. This could interfere with the interpretation of the usability testing and its subsequent use for program improvement or refinement. ${ }^{41}$ In the future, qualitative analyses should be included to report detailed and complementary data on program usability and participant opinions.

In sum, to the best of our knowledge, this is the first study to analyze patient acceptance of an Internet-based program that includes exposure scenarios composed of images and real sounds for the treatment of FP, while comparing two delivery methods - completely self-applied and self-applied with therapist guidance. NO-FEAR Airlines is presented as a well-accepted FP treatment self-applied via the Internet. This program helps to enhance the application of the exposure technique, improving patient acceptance and access to FP treatment. Further research - as, for example, to investigate whether there are sociodemographic variables that may influence the acceptance of these Internet-based programs - is needed. Finally, future research is required to develop increasingly sophisticated Internet-based programs that include different technologies (ie, persuasive technologies and more sophisticated and relevant exposure scenarios) in order to improve acceptance and access to evidence-based psychological interventions.

\section{Acknowledgments}

This study was supported by funding from the Ministerio de Economía y Competitividad (Spain; Plan Nacional I+D+I; grant no PSI2013-41783-R); Red de Excelencia (grant no PSI2014-56303-REDT) PROMOSAM, Research in processes, mechanisms and psychological treatments for mental health promotion from the Ministerio de Economía y Competitividad (2014); a PhD grant from Generalitat Valenciana (VALi+d; grant no ACIF/2014/320); and CIBER (CIBER Fisiopatología de la Obesidad y Nutrición is an initiative of ISCIII).

\section{Disclosure}

The authors report no conflicts of interest in this work. 


\section{References}

1. Andersson G. Internet-delivered psychological treatments. Annu Rev Clin Psychol. 2016;12:157-179.

2. Andrews G, Cuijpers P, Craske MG, McEvoy P, Titov N. Computer therapy for the anxiety and depressive disorders is effective, acceptable and practical health care: a meta-analysis. PLoS One. 2010;5(10): e13196.

3. Hedman E, Ljótsson B, Lindefors N. Cognitive behavior therapy via the Internet: a systematic review of applications, clinical efficacy and cost-effectiveness. Expert Rev Pharmacoecon Outcomes Res. 2012; 12(6):745-764.

4. Sijbrandij M, Kunovski I, Cuijpers P. Effectiveness of internet-delivered cognitive behavioral therapy for posttraumatic stress disorder: a systematic review and meta-analysis. Depress Anxiety. 2016;33(9): 783-791.

5. Mewton L, Smith J, Rossouw P, Andrews G. Current perspectives on Internet delivered cognitive behavioral therapy for adults with anxiety and related disorders. Psychol Res Behav Manag. 2014;7:37-46.

6. Olthuis JV, Watt MC, Bailey K, Hayden JA, Stewart SH. Therapistsupported Internet cognitive behavioural therapy for anxiety disorders in adults. Cochrane Database Syst Rev. 2016;3:CD011565.

7. Peñate W, Fumero A. A meta-review of Internet computer-based psychological treatments for anxiety disorders. J Telemed Telecare. 2016;22(1):3-11.

8. Reger MA, Gahm GA. A meta-analysis of the effects of internet- and computer-based cognitive-behavioral treatments for anxiety. J Clin Psychol. 2009;65(1):53-75.

9. Andersson G, Titov N. Advantages and limitations of Internet-based interventions for common mental disorders. World Psychiatry. 2014; 13(1):4-11.

10. Andrews G, Newby JM, Williams AD. Internet-delivered cognitive behavior therapy for anxiety disorders is here to stay. Curr Psychiatry Rep. 2015;17(1):533.

11. Peñate W. About the effectiveness of telehealth procedures in psychological treatments. Int J Clin Health Psychol. 2012;12(3):475-487.

12. Deacon BJ, Farrell NR. Therapist barriers to the dissemination of exposure therapy. In: Storch E, McKay D, editors. Handbook of Treating Variants and Complications in Anxiety Disorders. New York: Springer; 2013:363-373.

13. Garcia-Palacios A, Botella C, Hoffman H, Fabregat S. Comparing acceptance and refusal rates of virtual reality exposure vs. in vivo exposure by patients with specific phobias. Cyberpsychol Behav. 2007;10(5): $722-724$.

14. Olatunji BO, Deacon BJ, Abramowitz JS. The cruelest cure? Ethical issues in the implementation of exposure-based treatments. Cogn Behav Pract. 2009;16(2):172-180.

15. Kaltenthaler E, Brazier J, De Nigris E, et al. Computerised cognitive behaviour therapy for depression and anxiety update: a systematic review and economic evaluation. Health Technol Assess. 2006;10(33): iii, xi-xiv, 1-168.

16. Whitfield G, Williams C. If the evidence is so good-why doesn't anyone use them? A national survey of the use of computerized cognitive behaviour therapy. Behav Cogn Psychother. 2004;32(1):57-65.

17. Wallin EE, Mattsson S, Olsson EM. The preference for Internet-based psychological interventions by individuals without past or current use of mental health treatment delivered online: a survey study with mixedmethods analysis. JMIR Ment Health. 2016;3(2):e25.

18. Rush B, Scott RE. Approved telehealth outcome indicator guidelines: quality, access, acceptability and cost. Calgary, AB, Canada: Calgary Health Telematics Unit, University of Calgary; 2004.

19. Kazdin AE. Acceptability of alternative treatments for deviant child behavior. J Appl Behav Anal. 1980;13(2):259-273.

20. Santana L, Fontenelle LF. A review of studies concerning treatment adherence of patients with anxiety disorders. Patient Prefer Adherence. 2011;5:427-439.

21. Swift JK, Callahan JL. The impact of client treatment preferences on outcome: a meta-analysis. J Clin Psychol. 2009;65(4):368-381.
22. Botella C, Gallego MJ, Garcia-Palacios A, Baños RM, Quero S, AlcañizM. The acceptability of an Internet-based self-help treatment for fear of public speaking. Br J Guid Couns. 2009;37(3):297-311.

23. Botella C, Mira A, Moragrega I, et al. An Internet-based program for depression using activity and physiological sensors: efficacy, expectations, satisfaction, and ease of use. Neuropsychiatr Dis Treat. 2016; 12:393-406.

24. Botella C, Pérez-Ara MÁ, Bretón-López J, Quero S, García-Palacios A, Baños RM. In vivo versus augmented reality exposure in the treatment of small animal phobia: a randomized controlled trial. PLoS One. 2016;11(2):e0148237.

25. Greenberg RP, Constantino MJ, Bruce N. Are patient expectations still relevant for psychotherapy process and outcome? Clin Psychol Rev. 2006;26(6):657-678.

26. de Graaf LE, Huibers MJ, Riper H, Gerhards SA, Arntz A. Use and acceptability of unsupported online computerized cognitive behavioral therapy for depression and associations with clinical outcome. J Affect Disord. 2009;116(3):227-231.

27. Goossens ME, Vlaeyen JW, Hidding A, Kole-Snijders A, Evers SM. Treatment expectancy affects the outcome of cognitive-behavioral interventions in chronic pain. Clin J Pain. 2005;21(1):18-26; discussion 69-72.

28. Marks IM, Cavanagh K, Gega L. Computer-aided psychotherapy: revolution or bubble? Br J Psychiatry. 2007;191:471-473.

29. Bachofen M, Nakagawa A, Marks IM, et al. Home self-assessment and self-treatment of obsessive-compulsive disorder using a manual and a computer-conducted telephone interview: replication of a UK-US study. J Clin Psychiatry. 1999;60(8):545-549.

30. Bretón-López J, Tortella-Feliu M, del Amo AR, et al. Patients' preferences regarding three computer-based exposure treatments for Fear of Flying. Behav Psychology. 2015;23(2):265-285.

31. García-Palacios A, Hoffman HG, See SK, Tsai A, Botella C. Redefining therapeutic success with virtual reality exposure therapy. Cyberpsychol Behav. 2001;4(3):341-348.

32. Tarrier N, Liversidge T, Gregg L. The acceptability and preference for the psychological treatment of PTSD. Behav Res Ther. 2006;44(11): 1643-1656.

33. Montero-Marín J, Prado-Abril J, Botella C, et al. Expectations among patients and health professionals regarding web-based interventions for depression in primary care: a qualitative study. J Med Internet Res. 2015;17(3):e67.

34. Wootton BM, Titov N, Dear BF, Spence J, Kemp A. The acceptability of Internet-based treatment and characteristics of an adult sample with obsessive compulsive disorder: an Internet survey. PLoS One. 2011; 6(6):e20548.

35. Carrard I, Crépin C, Rouget P, Lam T, Golay A, Van der Linden M. Randomised controlled trial of a guided self-help treatment on the Internet for binge eating disorder. Behav Res Ther. 2011;49(8):482-491.

36. Gun SY, Titov N, Andrews G. Acceptability of Internet treatment of anxiety and depression. Australas Psychiatry. 2011;19(3):259-264.

37. Kay-Lambkin FJ, Baker AL, Kelly B, Lewin TJ. Clinician-assisted computerised versus therapist-delivered treatment for depressive and addictive disorders: a randomised controlled trial. Med J Aust. 2011; 195(3):S44-S50.

38. Kushniruk A. Evaluation in the design of health information systems: application of approaches emerging from usability engineering. Comput Biol Med. 2002;32(3):141-149.

39. Anderson P, Zimand E, Schmertz SK, Ferrer M. Usability and utility of a computerized cognitive-behavioral self-help program for public speaking anxiety. Cogn Behav Pract. 2007;14(2):198-207.

40. Castilla D, Garcia-Palacios A, Miralles I, et al. Effect of Web navigation style in elderly users. Comput Hum Behav. 2016;55:909-920.

41. Currie SL, McGrath PJ, Day V. Development and usability of an online CBT program for symptoms of moderate depression, anxiety, and stress in post-secondary students. Comput Hum Behav. 2010;26(6):1419-1426.

42. Stjernswärd S, Ostman M. Illuminating user experience of a website for the relatives of persons with depression. Int J Soc Psychiatry. 2011; 57(4):375-386. 
43. Andersson G, Waara J, Jonsson U, Malmaeus F, Carlbring P, Ost LG. Internet-based self-help versus one-session exposure in the treatment of spider phobia: a randomized controlled trial. Cogn Behav Ther. 2009; 38(2):114-120.

44. Andersson G, Waara J, Jonsson U, Malmaeus F, Carlbring P, Ost LG. Internet-based exposure treatment versus one-session exposure treatment of snake phobia: a randomized controlled trial. Cogn Behav Ther. 2013;42(4):284-291.

45. Botella C, Quero S, Banos RM, et al. Telepsychology and self-help: the treatment of phobias using the internet. Cyberpsychol Behav. 2008; 11(6):659-664.

46. Kok RN, van Straten A, Beekman AT, Cuijpers P. Short-term effectiveness of web-based guided self-help for phobic outpatients: randomized controlled trial. J Med Internet Res. 2014;16(9):e226.

47. Matthews A, Naran N, Kirkby KC. Symbolic online exposure for spider fear: habituation of fear, disgust and physiological arousal and predictors of symptom improvement. J Behav Ther Exp Psychiatry. 2015;47:129-137.

48. Matthews AJ, Wong ZH, Scanlan JD, Kirkby KC. Online exposure for spider phobia: continuous versus intermittent exposure. Behav Change. 2011;28(3):143-155.

49. Schröder J, Jelinek L, Moritz S. A randomized controlled trial of a transdiagnostic Internet intervention for individuals with panic and phobias - one size fits all. J Behav Ther Exp Psychiatry. 2017;54: 17-24.

50. Tortella-Feliu M, Botella C, Llabrés J, et al. Virtual reality versus computer-aided exposure treatments for fear of flying. Behav Modif. 2011;35(1):3-30.

51. Gilbody S, Littlewood E, Hewitt C, et al; REEACT Team. Computerised cognitive behaviour therapy (cCBT) as treatment for depression in primary care (REEACT trial): large scale pragmatic randomised controlled trial. BMJ. 2015;351:h5627.

52. Johansson R, Andersson G. Internet-based psychological treatments for depression. Expert Rev Neurother. 2012;12(7):861-869; quiz 870.

53. Richards D, Richardson T. Computer-based psychological treatments for depression: a systematic review and meta-analysis. Clin Psychol Rev. 2012;32(4):329-342.

54. Andersson G, Cuijpers P. Internet-based and other computerized psychological treatments for adult depression: a meta-analysis. Cogn Behav Ther. 2009;38(4):196-205.

55. Kelders SM, Bohlmeijer ET, Pots WT, van Gemert-Pijnen JE. Comparing human and automated support for depression: fractional factorial randomized controlled trial. Behav Res Ther. 2015; 72:72-80.

56. Mira A, Bretón-López J, García-Palacios A, Quero S, Baños RM, Botella C. An Internet-based program for depressive symptoms using human and automated support: a randomized controlled trial. Neuropsychiatr Dis Treat. 2017;13:987-1006.

57. Campos D, Bretón-López J, Botella C, et al. An Internet-based treatment for flying phobia (NO-FEAR Airlines): study protocol for a randomized controlled trial. BMC Psychiatry. 2016;16:296.

58. Eysenbach G; CONSORT-EHEALTH Group. CONSORT-EHEALTH: improving and standardizing evaluation reports of Web-based and mobile health interventions. J Med Internet Res. 2011;13(4): e126.

59. American Psychiatric Association. Diagnostic and Statistical Manual of Mental Disorders. Washington, DC: Elsevier; 2013.

60. Antony M, Orsillo SM, Roemer L. Practitioner's Guide to EmpiricallyBased Measures of Anxiety. New York: Kluwer Academic/Plenum Publishers; 2001.

61. Brown TA, Barlow DH, Di Nardo PA. Anxiety Disorders Interview Schedule for DSM-IV (ADIS-IV): Client Interview Schedule. New York: Graywind Publications Inc; 1994.

62. Di Nardo PA, Brown TA, Barlow DH. Anxiety Disorders Interview Schedule for DSM-IV: Lifetime Version (ADIS-IV-L). New York: Graywind Publications Inc; 1994.

63. Borkovec TD, Nau SD. Credibility of analogue therapy rationales. J Behav Ther Exp Psychiatry. 1972;3(4):257-260.
64. Quero S, Pérez-Ara MÁ, Bretón-López J, García-Palacios A, Baños RM, Botella C. Acceptability of virtual reality interoceptive exposure for the treatment of panic disorder with agoraphobia. Brit J Guid Couns. 2014; 42(2):123-137.

65. Bangor A, Kortum PT, Miller JT. An empirical evaluation of the system usability scale. Int J Hum-Comput Int. 2008;24(6):574-594.

66. Brooke J. SUS: a "quick and dirty" usability scale. In: Jordan PW, Thomas B, Weerdmeester BA, McClelland IL, editors. Usability Evaluation in Industry. London, UK: Taylor \& Francis; 1996:189-194.

67. Bangor A, Kortum P, Miller J. Determining what individual SUS scores mean: adding an adjective rating scale. J Usability Stud. 2009; 4(3):114-123.

68. Tortella-Feliu M, Bornas X, Llabrés J. Computer-assisted exposure treatment for flight phobia. Int J Behav Consult Ther. 2008;4(2):158-171.

69. Bornas X, Tortella-Feliu M, García de la Banda G, Fullana MA, Llabrés J. Validación factorial del cuestionario de miedo a volar (QPV) [The factor validity of the fear of flying questionnaire]. Anál Modif Conducta. 1999;25:885-907. Spanish [with English abstract].

70. Quero S, Campos D, Riera Del Amo A, et al. NO-FEAR Airlines: a computer-aided self-help treatment for flying phobia. Stud Health Technol Inform. 2015;219:197-201.

71. Melville KM, Casey LM, Kavanagh DJ. Dropout from Internet-based treatment for psychological disorders. Br J Clin Psychol. 2010;49(Pt 4): 455-471.

72. Spek V, Cuijpers P, Nyklícek I, Riper H, Keyzer J, Pop V. Internet-based cognitive behaviour therapy for symptoms of depression and anxiety: a meta-analysis. Psychol Med. 2007;37(3):319-328.

73. van Ballegooijen W, Cuijpers P, van Straten A, et al. Adherence to Internet-based and face-to-face cognitive behavioural therapy for depression: a meta-analysis. PLoS One. 2014;9(7):e100674.

74. Hilvert-Bruce Z, Rossouw PJ, Wong N, Sunderland M, Andrews G. Adherence as a determinant of effectiveness of internet cognitive behavioural therapy for anxiety and depressive disorders. Behav Res Ther. 2012;50(7-8):463-468.

75. Kelders SM, Kok RN, Ossebaard HC, Van Gemert-Pijnen JE. Persuasive system design does matter: a systematic review of adherence to web-based interventions. J Med Internet Res. 2012;14(6):e152.

76. Musiat P, Tarrier N. Collateral outcomes in e-mental health: a systematic review of the evidence for added benefits of computerized cognitive behavior therapy interventions for mental health. Psychol Med. 2014;44(15):3137-3150.

77. Baumeister H, Reichler L, Munzinger M, Lin J. The impact of guidance on Internet-based mental health interventions - a systematic review. Internet Interv. 2014;1(4):205-215.

78. Karyotaki E, Riper H, Twisk J, et al. Efficacy of self-guided Internetbased cognitive behavioral therapy in the treatment of depressive symptoms: a meta-analysis of individual participant data. JAMA Psychiatry. 2017;74(4):351-359.

79. Lancee J, van den Bout J, Sorbi MJ, van Straten A. Motivational support provided via email improves the effectiveness of internet-delivered self-help treatment for insomnia: a randomized trial. Behav Res Ther. 2013;51(12):797-805.

80. Titov N, Andrews G, Schwencke G, Solley K, Johnston L, Robinson E. An RCT comparing effect of two types of support on severity of symptoms for people completing Internet-based cognitive behaviour therapy for social phobia. Aust N Z J Psychiatry. 2009;43(10):920-926.

81. MacGregor AD, Hayward L, Peck DF, Wilkes P. Empirically grounded clinical interventions clients' and referrers' perceptions of computerguided CBT (FearFighter). Behav Cogn Psychother. 2009;37(1):1-9.

82. Titov N, Andrews G, Davies M, McIntyre K, Robinson E, Solley K. Internet treatment for depression: a randomized controlled trial comparing clinician vs. technician assistance. PLoS One. 2010;5(6):e10939.

83. Bornas X, Tortella-Feliu M, Fullana MA, Llabrés J. Computerassisted treatment of flight phobia: a controlled study. Psychother Res. 2001;11(3):259-273.

84. Bornas X, Tortella-Feliu M, Llabrés J. Do all treatments work for flight phobia? Computer-assisted exposure versus a brief multicomponent non-exposure treatment. Psychother Res. 2006;16:41-50. 
85. Mühlberger A, Wiedemann G, Pauli P. Efficacy of a one-session virtual reality exposure treatment for fear of flying. Psychother Res. 2003;13(3): 323-336.

86. Carvalho ML, Guimarães H, Ferreira JB, Freitas A. Intention to use M-learning: an extension of the technology acceptance model. In: 19th International Conference on Recent Advances in Retailing and Consumer Services Science; July 9-12, 2012; Vienna, Austria.

87. Davis FD. Perceived usefulness, perceived ease of use, and user acceptance of information technology. MIS Quart. 1989;13(3):319-340.

88. Davis FD, Bagozzi RP, Warshaw PR. Extrinsic and intrinsic motivation to use computers in the workplace. J Appl Soc Psychol. 1992;22(14): 1111-1132.

89. Huang TL, Liao S. A model of acceptance of augmented-reality interactive technology: the moderating role of cognitive innovativeness. Electron Commer Res. 2015;15(2):269-295.

90. Kazdin AE, Rabbitt SM. Novel models for delivering mental health services and reducing the burdens of mental illness. Clin Psychol Sci. 2013;1(2):170-191.

91. Boettcher J, Berger T, Renneberg B. Does a pre-treatment diagnostic interview affect the outcome of Internet-based self-help for social anxiety disorder? A randomized controlled trial. Behav Cogn Psychother. 2012;40(5):513-528.
92. Buchanan T, Johnson JA, Goldberg LR. Implementing a five-factor personality inventory for use on the Internet. Eur J Psychol Assess. 2005;21(2):115-127.

93. Campos D, Quero S, Bretón-López J, et al. Concordancia entre la evaluación psicológica a través de Internet y la evaluación tradicional aplicada por el terapeuta para la fobia a volar. [Correlation between psychological evaluation through the Internet and traditional evaluation applied by the therapist for flying phobia]. Tesis Psicológica. 2015;10(2):52-67. Spanish [with English abstract].

94. Carlbring $\mathrm{P}$, Brunt $\mathrm{S}$, Bohman $\mathrm{S}$, et al. Internet vs. paper and pencil administration of questionnaires commonly used in panic/agoraphobia research. Comput Hum Behav. 2007;23(3):1421-1434.

95. Hedman E, Ljótsson B, Blom K, et al. Telephone versus internet administration of self-report measures of social anxiety, depressive symptoms, and insomnia: psychometric evaluation of a method to reduce the impact of missing data. J Med Internet Res. 2013;15(10):e229.

96. Hedman E, Ljótsson B, Rück C, et al. Internet administration of self-report measures commonly used in research on social anxiety disorder: a psychometric evaluation. Comput Hum Behav. 2010;26(4): 736-740.
Neuropsychiatric Disease and Treatment

\section{Publish your work in this journal}

Neuropsychiatric Disease and Treatment is an international, peerreviewed journal of clinical therapeutics and pharmacology focusing on concise rapid reporting of clinical or pre-clinical studies on a range of neuropsychiatric and neurological disorders. This journal is indexed on PubMed Central, the 'PsycINFO' database and CAS,

\section{Dovepress}

and is the official journal of The International Neuropsychiatric Association (INA). The manuscript management system is completely online and includes a very quick and fair peer-review system, which is all easy to use. Visit http://www.dovepress.com/testimonials.php to read real quotes from published authors. 